\title{
THE EFFECT OF CONTACT STRESS INTENSITY FACTOR ON FATIGUE CRACK PROPAGATION UNDER VARIABLE AMPLITUDE LOADING
}

Y. C. Lam and J. F. Williams

Department of Mechanical Engineering, Melbourne University, Victoria 3052, Australia

ABSTRACT

The phenomenon of crack closure is modelled by a "Contact Stress Intensity Factor" Ko Factor" Ko mea co no load prodeting loading as long as $\mathrm{K}_{\max }$ is kept interaction of $\mathrm{K}_{\mathrm{max}}$ in step-down loading, crack retardation will will the experimentally observed retarded crack growth rates. The disagreement between the suggested relationship for the variation of Kc during

crack retardation and the measured values can most probably be explained by the observed crack branching after step-down loading. From previous work by Lam and Williams $(1982,1984)$, it is demonstrated that Kc can explain the effect under constant amplitude loading. This implies that crack closure modelled on the basis of $K c$ can explain the effect of $\mathrm{R}$, crack retardation and crack arrest and reveals that all these phenomena to one another.

$$
\text { KEYWORDS }
$$

Crack closure; contact stress intensity factor; crack retardation; crack arrest; variable amplitude loading.

INTRODUCTION

The The effect of Contact stre loading has been investigated by Lam and Williams under constant amplitude loading has be of crack closure, the effect of $\mathrm{B}$ (1982,1984\%. Using Kc for the Hodelling of creck can be accounted for.

$$
\begin{aligned}
& \mathrm{Ka}=\mathrm{K}+\mathrm{Kc} \\
& \mathrm{Ka}_{\max }=\mathrm{K}_{\max }
\end{aligned}
$$




$$
\begin{aligned}
& K a_{\text {min }}=K_{\text {min }}+K c_{\text {max }} \\
& \Delta R=K_{\text {max }}-K_{\text {min }} \\
& K \mathrm{Kc}_{\max }=f(R) \Delta K \\
& \Delta K e=K a_{\text {max }}-K a_{\text {min }}-K^{*} \\
& =K_{\text {max }}-\left(K_{\text {min }}+K c_{\text {max }}\right)-K^{*} \\
& =\Delta K-K c_{\text {max }}-K^{*}
\end{aligned}
$$

$\mathrm{da} / \mathrm{dn}=\mathrm{f}(\Delta \mathrm{Ke})$

where

$K=$ Stress Intensity Factor due to the applied loads. $\mathrm{Ka}=$ Actual Stress Intensity

$\Delta K e=$ The Fffective Stress Intensity Factor Range causing fatigue crack growth.

* faticue crack growth. (Threshold Stress Intensity Factor)

$\mathrm{da} / \mathrm{dn}=$ Crack growth rate.

The subscripts max and min indicate respectively the maximum and minimum values of the appropriate parameter in a loading cycle.

In the existing literature, crack closure is modelled by using the crack In the existing literature, crack elosur (1970, 1971). However, as opening stress $\sigma$ as proposed by Elber (197), Chanani and Mays (1977), Brown demonstrated by Sharpe and co-workers (1976), and Weertman (1978) and Gan and Weertman (1981), $\sigma o p$

che retardation under vatigue Thus, it is a natural extension to investigate the effect of Kc on fat crack propagation under variable amplitude loading. For the pres.

of $K c$ is based on the compressive It should be pointed out that the concept of Kc is based on thesure. In these stress developed along the wake of the crack urrest Method. investigations, $K c$ is deduced experiment procedure employed for the Details of the concept and the experme (1984). Thus, both determination of Kc may bent of Kc are different from Elber's $\sigma_{o p}$.

\section{TWO-STEP BLOCK LOADING WITH CONSTANT $\mathrm{K}_{\max }$}

The first type of two-step block loading to be examined is one with constant $K_{\max }$ but different $K_{\min }$ as shown in Fig. 1 .

max Considering that crack closure occurs during the unjoading in or the cycle, it is reasonable to assume that $K c$ is a continuous $\mathrm{K}$. unloading. At any point along the unloading path, $K c$ has a fin $K_{c}$. It changing value, varying from zero to $\mathrm{kax}$ to a maximum is further reasonable to suggest that una ${ }^{\prime} \mathrm{kc}$ is governed by an equation

any point of the unloading path,
similar to equation 5 . That is:-

$$
K c=f\left(R_{p}\right) \Delta K_{p}
$$



(b)

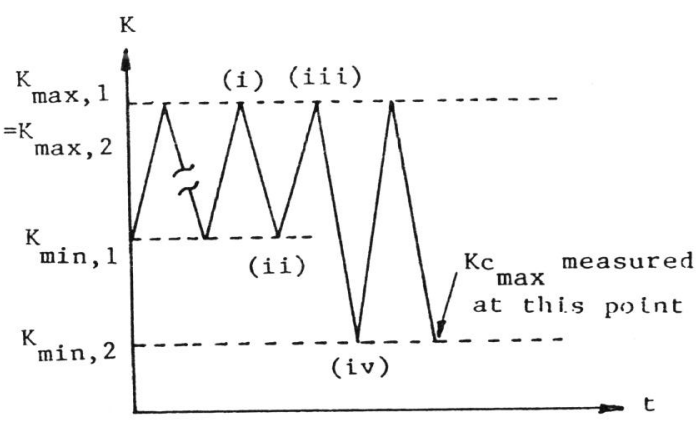

Fig. 1. Two-step block loading with constant $\mathrm{K}_{\max }$

where the subscript $p$ indicates the value of the variable at any point on the where the subscript $p$ indicates the subscripts 1 and 2 will be use unloading path to denote quanti

Thus, for the case depicted in Fig. la, Kc max for unloading from (i) to (ii) will be given by :-

$$
\mathrm{Kc}_{\max , I}=\mathrm{f}\left(\mathrm{R}_{I}\right) \Delta \mathrm{K}_{I}
$$

wichis the valuef a constant amplitude loading for block one.

Unloading from (iii) to (iv) is similar to partially unloading from (i) to

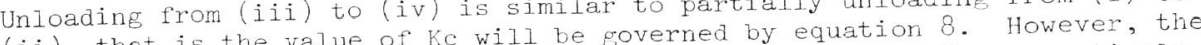
(1i), that $1, \mathrm{~B}_{\mathrm{p}}$ and $\Delta \mathrm{K}_{\mathrm{P}}$ are the values of $\mathrm{Kc}_{\max }, 2, \mathrm{R}_{2}$ and $\Delta \mathrm{K}_{2}$ respectively. That is :-

$K c_{\max , 2}=f\left(R_{2}\right) \Delta K_{2}$

Comparing equation 10 with equation 5 , the value of $K c_{\max }, 2$ turns out to be value 
amounts to saying that for the case shown in Fig. la where $K_{\max }$ remains constant, a sudden change in $K_{\text {min }}$ will not produce any transient or load under constant amplitude loading instantaneously.

A similar argument may be applied to the case as shown in Fig. Ib, provided that Kc will still be governed by equation 8 even when $\Delta K_{1}$ is less than $\Delta K_{2}$.

From the above analysis, it may be generalised that as long as $\mathrm{K}$ max remains unchanged, there will be no load interaction effect. This is in maxct observed experimentally by McMillan and Pelloux (1967), Porter (1972) Wei and co-workers (1973) and Druce and co-workers (1979).

To confirm the above hypothesis that $\mathrm{Kc}$, will adjust itselt instantaneously if $\mathrm{K}_{\text {max }}$ is kept constant, the value of $\mathrm{KC}_{\text {max }}$ was measured using the Crack Arrest Method after two cycles of block two loading were applied. The loading sequences are indicated in Fig.I and the results are tabulated in Table 1.

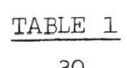

Specimen No.

${ }_{\mathrm{R}} \mathrm{K}_{1}$ 30

Fig. 1a
34.82

0.0

$\mathrm{KC}_{\max , 1 .}$ (cal.) $\underset{(\mathrm{MNm}-3 / 2)}{(\mathrm{MNm}-3 / 2)}$

$\mathrm{R}$

$\mathrm{Kc}_{\max , 2}$ (cal.) (MNm $-3 / 2$

$\mathrm{Kc}_{\max , 2}$ (mea.) (MNm $-3 / 2$ )

17.63

0.5
4.89

5.04

$$
\begin{gathered}
29 \\
\text { Fig. 1b } \\
17.65 \\
0.5 \\
4.90 \\
34.87 \\
0.0 \\
16.06 \\
15.20
\end{gathered}
$$
In Table 1 , the values of $\mathrm{Kc}_{\max }$ and $\mathrm{Kc}$ max $\mathrm{I}_{2}$ were calculated using equation 5. Kc max 2 was measured expertme value of Kc adjusts instantaneously to the the to block two losing. The difference between the calculated values of $\mathrm{Kc}$ for block two (assuming constant amplitude loading) and the measured values are in agreement, with only $4 \%$ and $5 \%$ difference between them for the loading sequence as shown in Fig. la and $1 \mathrm{~b}$.

\section{STEP-DOWN LOADING}

In the step-down loading sequence shown in Fig. 2, both crack arrest and retardation will be discussed.

\section{Crack Arrest}

On unloading from (i) to (ii), Fig. 2, Kc $\mathrm{may}_{\text {is }}$ is given by the constant amplitude value, that is according to equation 9:-

$$
K c_{\max , I}=f\left(\mathrm{r}_{1}\right)\left(\mathrm{K}_{\max , I}-K_{\min , I}\right)
$$

On loading from (ii) to (iii), $\Delta \mathrm{Ke}$, according to equation 6 , is given by:-

$$
\Delta K e=\Delta K_{2}-K c_{\max , I}-K^{*}
$$

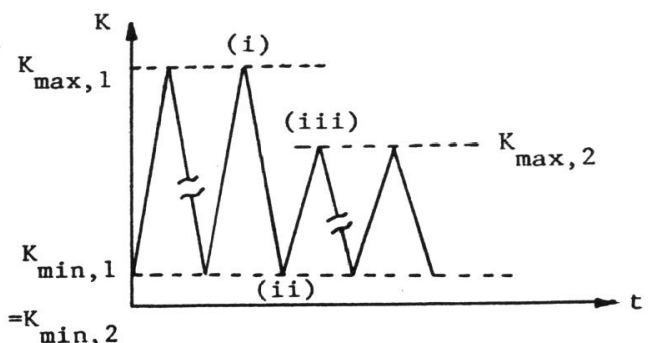

Fig. 2. Step-down loading.

Thus from equation 7 , crack arrest occurs when $\Delta \mathrm{Ke}=0$, that is:$\Delta K_{2}<f\left(R_{1}\right)\left(\Delta K_{1}\right)+K^{*}$

In the following discussion of crack arrest, the effect of $K^{*}$ will be ignored. The reason being that if the applied stress intensity factor is ignor be small and negligible when compared with $\mathrm{K}_{\max }$ and $\mathrm{K}_{\min }$ Note that $\Delta K e$ cannot be negative since a negative $\Delta K e$ is meaningless. This implies that for crack arrest, from

$\mathrm{Ka}_{\min }=\mathrm{Ka}_{\max }$

indicates that the second line of equation 6 is obtained A closer examination indicates that the second maximum load, the crack is by assuming $\mathrm{Ka}_{\max }=\mathrm{K}_{\max }{ }^{\circ}$, This means that at maximum load, the crack arrest, at $\mathrm{K}_{\mathrm{mex}}$ there will still be crack closure. This implies that at $\mathrm{Ka}_{\max }$ will be max sum of $\mathrm{K}_{\max }$ and $\mathrm{Kc}$ associated with $K_{\max }$ at that instant. In fact, if $K$ and $K c$ are the applied and contact stress Intensity lactors at any point arrest, equation 13 becomes ing path with $\mathrm{K}$ greater that $\mathrm{K}_{\mathrm{min}}$ and with crack arrest, equation 13 becone

$\mathrm{K}_{\text {min }}+\mathrm{Kc}_{\max }=\mathrm{K}+\mathrm{Kc}$

When crack arrest occurs, according to equation 13, the actual stress intensity factor experienced by the crack tip material is constant since $\mathrm{Ka}_{\mathrm{min}}=\mathrm{Ka}$ at all times. From equation 14 , this is brought about by the interaction of the contact stress intensity factor due to crack closure and the applied stress intensity factor. As the latter increass crack closure and thus Kc, decreases.

Therefore with crack arrest, the crack tip material experiences no change in "There the strar condition before the occurrence of crack arrest. The number of loading cycles experienced during that period of crack arrest will not alter the subsequent behaviour. If at any time, the loading level is raised such the subsequenth occurs, the behaviour of crack growth will then be dictate by the conditions existing just before crack arrest.

Trperiat by wei and co-workers (1973) indicate that the Fxperimental observations by wei and com number of cycles during which the crack is arrested has neglisible to the the subsequent
above analysis.

AFR VOL $3-E^{\star}$ 
1684

\section{Crack Retardation}

From the above discussion, it is apparent that the onset of crack arrest is ( crack retardation, it is reasonat consider that crack retardation is governed by the same condition.

As the crack propagates under block two loading, the value of Ka min will change. It is reasonable to assume that the magnitude of values in block two various quantities from their consan the change. Thus the relevant will in turn affect the way in which they change.

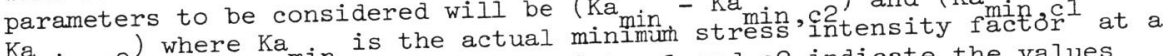
Kamin ${ }^{2}$ ) where Kamin is the actual mins ${ }^{2}$ and $c 2$ indicate the values associated with constant amplitude loading for block one and block two respectively.

Further, immediately after step-down loading, the conditions ahead and in the whe crack propagates under wake of the crack are thill slowly decay. Thus, crack block distance the crack propagates into the retardation should barameters should then monotonic plastic include $\left(a-a_{0}\right)$ and $d_{1}$ where ance of stepping down and $d_{1}$ is the monotonic plastic zone due to $\mathrm{K}_{\max } \mathrm{I}^{\text {. }}$

Based on the parameters identified above, it is proposed that:

$\left.\left(\mathrm{Ka} a_{\min }-\mathrm{Ka} \min , \mathrm{c2}\right) /\left(\mathrm{Ka} \min , \mathrm{cl}-\mathrm{Ka} a_{\min , \mathrm{c2}}\right)=\mathrm{g}\left[\left(\mathrm{a}-\mathrm{a}_{0}\right) / \mathrm{a}_{1}\right)\right]$

boundary conditions to be satisfied are:-

$$
\begin{array}{lll}
\mathrm{a}-\mathrm{a}_{0}-0 & \mathrm{Ka}_{\text {min }}=\mathrm{Ka} a_{\min , \mathrm{cl}} & \mathrm{g}=1.0 \\
\mathrm{a}-\mathrm{a}_{0} \rightarrow \infty & \mathrm{Ka}_{\text {min }}=\mathrm{Ka} a_{\text {min }, \mathrm{c} 2} & \mathrm{~g}=0.0
\end{array}
$$

may be calculated according to If $\mathrm{Kc}$ is known, the values of $\mathrm{Ka}_{\text {min }}$ may be calculated aco under block two equation 3 . In this investigation, as the crack propagated under crack loading, $\mathrm{Kc}$. was measured as a function of crack length using limits and Arrest Method. Two specimens were used for each set of

, equation 3 was used. However, For the calculation of $\mathrm{Kamin}, \mathrm{cl}$
the value of $\mathrm{Ka} \mathrm{min}_{\max }$ was obtaine equ
thing equation 5 .

To calculate $\mathrm{d}_{3}$, in order to take into account the effect of the finite tocimen size, Rice's (1966) longitudinal shear solution for an elastic perfectly plastic material and the analogy between longitudinal shear and tensile loading (McClintock, 1961; McClintock and Irwin, 1965) was utiliaed Alternatively the value of $\mathrm{Ka}$ min may be calculated through the measurement of $\mathrm{da} / \mathrm{dn}$. If $\mathrm{da} / \mathrm{dn}$ is known, dhe may be obtained from the logation 6 , with $\mathrm{da} / \mathrm{dn}$ versus $\Delta \mathrm{Ke}$, see Lam and Williams (1984). Then from. The value of $\mathrm{K}^{*}$ may the value of $K_{\max }$ and $K^{*}$ known, Ka migay . For the measurement of da/dn after be obtained for was for each loading limit. It step-down loading, a different specimen was ustained independently by either should be noted that is the the da/dn Method agree, then a rational the crack Arest Me substantiated.
Two loading conditions were investigated with $\mathrm{R}$ approximately equal to zero. The results are shown in Fig. 3 with the parameter $\left(\mathrm{Ka}_{\mathrm{min}}-\mathrm{Ka}_{\mathrm{min}, \mathrm{c2}}\right) /$

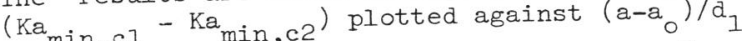

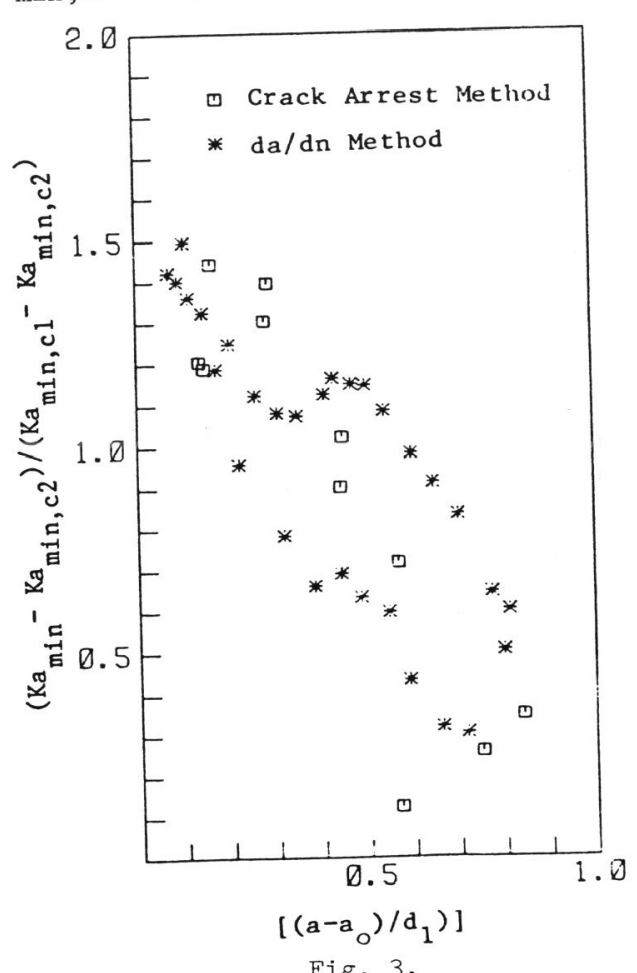

From Fig. 3 it can be seen that indeed excellent agreement is

obtained between the values or Kamin measured by the Crack Arre
Method and by the da/dn method.

This indicates that the phenomenon or crack closure as modelled by Kc erack retardation.

A close examination of Fig. 3 A close exanination oe rig. 3 condition as stated in equation 16 for the relationship proposed by for the relation to be At $a-a=0$, the function g $[(a-a) / d]$ assumes a value proxiotety equal to 1.5 instead f 1.0 as required. The higher value of the function indicates a higher value of $\mathrm{Ka}_{\min }$ and $\mathrm{Kc}_{\max }$ than expected.

A possible explanation of the above discrepancy is due to the effect of crack branching which was commonly observed after step-down loading. The interaction between the two different branched cracks may bring about a higher value of $\mathrm{Kc}_{\max }$. It should also be noted that the parameter ( $\mathrm{Ka}_{\text {min }}-\mathrm{Ka}$ min $\left.{ }_{\mathrm{c}} \mathrm{C}\right)$ is the measurements of $\mathrm{Ka}_{\text {min }}$ may bring large changes in the value of the Showing the variation of Ka parameter

as the crack propagated under block two loading.

CONCLUSION

Using the Using the concept of crack by Lam and Williams $(1982$, 1984) that the Factor Kc, it was demons loading can be accounted for.

effect of $\mathrm{R}$ under constant amplitude loading can be accounted for.

Under two-step block loading, using $K c$, it is further predicted and load demonstrated that as long as $K_{\max }$ is kept constant, thellent experimental interaction effect with chan of $\mathrm{Kc}$ and its effect on the agreement was obtainedion rate after a reduction of $\mathrm{K}_{\max }$ where crack growth fatigue crack proparied. To the best knowledge of the authors, it is the retardation was obed a reement has been obtained between the measured value first time that good agreened crack growth. Since Kc is measured by the Crack 
Arrest Method, this further implies that using the concept of crack closure, the phenomena of crack arrest and crack retardation under variable amplitude loading and the $\mathrm{R}$ effect under constant amplitude loading are intimately

related to one another.

Disagreement exists between the suggested relationship as defined by equation 16 for the variation of $\mathrm{Ka}_{\text {min }}$ during crack retardation and the experimental observations. A higher values of $\mathrm{Ka}_{\min }$ and 'Ke were observed. This most

probably can be explained by the presence of crack branching after step-down laading. With crack branching, due to the interaction of the branched cracks, This will then give rise to a higher calculated value of crack closure.

REFERENCES

Brown R.D. and J. Weertman (1978). Effects of tensile overloads on crack closure and crack propagation rates in 7050 aluminium. Engineering Fracture Mechanics, 10, 867-878.

Chanani G.R. and B.J. Mays (1977). Observation of crack closure behaviour after single overload cycles in 7075-T6 single-edged-notched specimens. Engineering Fracture Mechanics, 9, 65-73

Druce S.G., C.J. Beevers and E.F. Walker. Fatigue crack growth retardation following load reduction in a plain C-MN steel. Engineering Fracture Mechanics, 11, 385-395.

Elber, W. (1970). Fatigue crack closure under cyclic tension. Engineering Fracture Mechanics, 2 , 37-45.

Elber, W. (1971). The significance of fatigue crack closure. Damage Eolerance in Aircraft Structures, A.S.T.M. STP 486, 230-242,

Gan D. and J. Weertman (1981). Crack closure and crack propagation rates in 7050 aluminium. Engineering Fracture Mechanics, 15, 87-106.

Lam, Y.C. and J.F. Williams (1982). The effect of contact stress intensity factors on fatigue crack propagation. Proceedings International
Conference on Fracture Mechanics Technology applied to Material Evaluation and Sturcture Design, Melbourne University, 517-528.

Lam, Y.C. and J.F. Williams (1984). The effect of contact stress intensity factors on fatigue crack propagation. Fracture Mechanics and Technology. Accepted for publication.

McClintock F.A. (1961). Discussion of paper on fracture testing of highstrength sheet material. Material Research and Standards, April, 277-279. inonics. Fracture T.T.M. STP $381,84-113$

Mclillan J. C and R.M. N Pelloux (1967). Fatigue crack propagation under program and random loads. Fatigue Crack Propagation, A.S.T.M. STP 415 (505-535.

Porter, T.R. (1C 72$)$. Method of analysis and prediction for variable ampituth. Engineering Fracture Mechanics, 4,

17-736.

Rice, J.C. (1966). Contained Pnternational Journal of Fracture Mechanics, June, $426-447$.

Sharpe W.N., D.M. Corbly and A.F. Grandt Jr. (1976). Effects of rest time on fatigue crack retardation and observations of crack closure. Fatigue Crack Growth under Spectrum Loads, A.S.T.M. STP 595, 61-77.

Wei, R.P.T.T. Shih and J.H. Fitzgerald(1973). Load interaction effects on fatigue grack growth in Ti-6AL-4V alloy. NASA CR-2239, April, National Aeronautics and Space Administration, Washington, D.C. 20546. 